\title{
SUSPENDED SEDIMENT TRANSPORT IN COASTAL ZONE BY TIDAL FLOW PART I: MODELS OF SPM VERTICAL DISTRIBUTION
}

\author{
Antsyferov S. M. And Akivis T. M. \\ Russian Academy of Sciences, P. P. Shirshov Institute of Oceanology, \\ Nakhimovsky prospect, 36, Moscow, 117997, Russia
}

\begin{abstract}
The aim of the study is to develop methods for prediction of the vertical distribution of characteristics of sand and aleurite sediment suspended by tidal flow for the averaging time either divisible by tidal period (the first order model) or much less than it is (the second order one). The bottom is assumed to be erodible with possible formation of ripples.

Part I: The theoretical and laboratory study of steady flow with suspension is used to develop the solution. The concentration field of heterogeneous sediment is considered as a sum of those of homogeneous groups of particles (fractions) moving under the same regulations. In the first order model, the hydrodynamical characteristics of the tidal flow are represented by their constant effective values. In the second order model the tidal flow is represented by the series of consecutive steady states (steps).
\end{abstract}

\section{Introduction}

The models of transport and distribution of sand and aleurite sediment suspended from the seabed by tidal flow are developed and verified. An erodible seabed is the most substantial source of sediment feed for the tidal flow in coastal zone, and parameters of bottom material, that can be uniquely determined, are among the necessary arguments for the problems relating to sediment transport. Particulates from the other sources, e.g. rivers discharge, islands abrasion, etc., can be found in suspension as well, but they are very fine, very slow settling ones. The prediction of their transport is a regional problem. because it needs the data of sediment sources and migration paths. This component of suspended sediment flow is ignored in present work.

It is well to take into account that intensive flow is capable of not only sediment pick-up from the bottom but also of formation of dynamic bottom microrelief. Ripples of time variant, during tidal period, size are formed on the bottom. They form bottom roughness and near bottom eddy structure, and thus, in their turn, influence considerably the suspension field. In tidal basins, erosion of microforms is occasionally observed and the flow propagates over the flat bed where the resistance to the flow depends on the particles roughness. The interrelation and interference between sediment pick-up and bottom deformation undoubtedly should be taken into account. In some cases, relief microforms are formed on the surface of slow moving large-scale sand waves of the other origin-that can be considered as topography elements because of their size.

The mass of suspended sediment travelling through the station or through the site is of 
great importance for many prediction problems in geophysics. Depending of the prediction objective, different averaging times should be chosen. For example, to find the bulk of deposited sediment in a channel the averaging time could be taken comparable to tidal period or even several periods. At the same time, for many problems not only the total sediment transport should be known but its distribution in time and space as well. Some of these problems need the infonuation of suspended sediment composition. It seems that the minimum time period for the correct solution of the problem of sediment transport is the time interval of quasi-steady state within the tidal period. The models of different averaging time and, accordingly, of different prognostic potential will be considered below.

It should be remembered that only limited field data arrays collected in coastal zone of tidal sea are available as original data for this prediction. Usually these are the data on sea level time variation and current velocity at certain horizon and the granulometric data on bottom sediment in the area under investigation.

\section{Problem statement}

From the above reasoning, the problem is set to develop a prediction method of vertical distribution of sand and aleurite sediment mass suspended and transported through the station for the part of tidal period, or one, or several periods, on the base of data on bottom sediment composition, sea level, and current velocity at certain horizon. Besides, the problem of suspended particulate matter (SPM) concentration and statistical characteristics vertical distribution will be considered. The part of tidal period is interpreted here as time interval for which hydro- and litho-dynamic condition could be considered as stationary. This interval is evidently much shorter than the tidal period itself. Thus the basic model for the problems is that of vertical distribution of SPM concentration in steady staite flow.

The bottom material is assumed to include comparatively light particles (in relation to the energy of turbulent pulsation) that can follow all water motions, particles with noticeable inertial properties and, at last, heavy particles that cannot be picked up from the bottom. The change of parameters of bottom micro-relief fonus during tidal period is also taken into account.

This approach takes into consideration a number of essential factors that remain to be adequately represented in theoretical models of a sediment-laden tidal flow. This is the cause for recruiting comparatively simple theoretical basis, together with empirical results approved by the wide practice of sea and channel research to construct the solution. ,

There are two possible stages of solution of the problem, namely the models of the first and the second order. Time averaging over a period of one or several intervals between the low water states is applied for the first order models. Only some effective characteristics of changing hydro- and litho-dynamic condition are used at this stage. In the second order models the tidal flow is considered as a series of comparatively short steady states within the tidal period. The latter approach is, clearly, more rigorous but it needs more initial data. In case they are not reliable enough and the reliability of the final result would be doubtful. At the same time, the former approach allows to propose a simpler forecast and, the main thing, provides more possibilities for comparison of the model results with 
observational data. Because of this developing of both types of models seems reasonable.

\section{The main aspects of the basic model}

1. The diffusion model of SPM vertical distribution will be used. There are enough evidences (summatized in Marchuk, Kagan, 1991; Van Rijn, 1993) of the clearly pronounced logarithmic profile of the mean current velocity during the tidal period. The exception is flow propagation over the bed forms of the length comparable to the flow depth. But this case is excluded from our consideration.

So, it can be assumed that, in the flow body, at least in its part where the coefficients of sediment turbulent diffusion $\varepsilon$ and turbulent kinematic viscosity $\eta$ are close to each other, the vertical distribution of normalized SPM concentration $\frac{C(y)}{C_{a}}$ is described satisfactorily by the known Rouse solution:

$$
\frac{C(y)}{C_{a}}=\left(\frac{H-y}{y} \frac{a}{H-a}\right)^{\frac{\omega}{v_{*}}}=R(y)
$$

where $(y)$ is SPM concentration at the level $y$ above bottom, $C_{a}$ is the concentration specified at some reference horizon $a, H$ is flow depth, $v_{*}$ is bottom shear stress, $\kappa$ is von Karman constant, $\omega$ is settling velocity of sediment particles.

2. The SPM concentration field over the seabed covered with inhomogeneous sediment is assumed to be the sum of $n$ concentration fields of homogeneous groups of particles (fractions) that are governed by similar laws. The superposition principle is applied not only to the particles motion in suspension but to flow-bottom exchange processes and to particles motion on the bed as well. In other words, the interaction between bottom and saltating particles is not assumed to change noticeably the behaviour of each selected fraction. The question of the correctness of this assumption is discussed in detail in by Debol'skii et al, (1999), where the validity of the approach was corroborated by a wide range of experimeptal data. According to this assumption, the formula (3.1) can be rewritten for the inhomogeneous sediment as follows:

$$
C(y)=\sum_{i=1}^{n} C_{a, i}\left(\frac{H-y}{y} \frac{a}{H-a}\right)^{\frac{\omega_{i}}{v_{*}}}=\sum_{i=1}^{n} C_{a, i} R_{i}(y),
$$

where $C_{a, i} \sim p_{i}$ and $p_{i}$ is the percentage of $i$-th fraction in the bed material.

3. The recruited solution has certain pitfalls, including unjustified near-surface concentration slump up to the zero at the surface itself. But this part of the flow carries the negligible amount of suspended sediment. In the main body of the flow, where $\varepsilon \cong \eta$, this solution differs little from the more rigorous ones. But, for $\varepsilon<\eta$, the inertia of particles results in increase of concentration gradients compared to that given by (3.2). Essential discrepancies appear usually for some sand fractions in the near-bottom area and, for these cases, the solution needs some adjustment by experimental data. The method proposed by Antsyferov, Debol'skii, (1997); Debol'skii et 
al, (1999) is one of the simplest and, at the same time, is supported by experimental results. An additional factor is put in formulae (3.1) and (3.2):

$$
\begin{array}{r}
C_{i}(y)=C_{a, i} R_{i}(y) F_{i}^{Q(y)}, \\
C(y)=\sum_{i=1}^{n} C_{a, i} R_{i}(y) F_{i}^{Q(y)},
\end{array}
$$

where

$$
F_{i}=\left\{\begin{array}{ccc}
1 & \text { if } & \frac{\omega_{i}}{v_{*}} \leq 3.7 \times 10^{-2} \\
-0.36 \ln \left(1.7 \frac{\omega_{i}}{v_{*}}\right) & \text { if } & 3.7 \times 10^{-2}<\frac{\omega_{i}}{v_{*}}<0.59 \\
0 & \text { if } & \frac{\omega_{i}}{v_{*}} \geq 0.59
\end{array}\right.
$$

and

$$
Q(y)=\tanh \left[5.7\left(\frac{y}{H}-\frac{a}{H}\right)\right] .
$$

The boundary condition for the solution in the range $3.7 \times 10^{-2}<\frac{\omega_{i}}{v_{*}}<0.59$ is given as the concentration at the reference level a

$$
\begin{aligned}
& C_{a, i}=A_{\tau} v_{*}^{3}(\nu g)^{-\frac{2}{3}} \rho_{*}^{-\frac{1}{2}} \omega_{i}^{-1} p_{i}, \\
& C_{a}=A_{\tau} v_{*}^{3}(\nu g)^{-\frac{2}{3}} \rho_{*}^{-\frac{1}{2}} \omega_{i}^{-1} p_{i},
\end{aligned}
$$

where $A_{c}=2 \times 10^{-5}$ for the flat bed and $A_{c}=4 \times 10^{-5}$ for rippled bed.

The values $C_{a}$ and $C_{a, i}$ in (3.7) and (3.8) are defined by weight of solid particles in water, $\rho^{*}=\frac{\rho_{s}-\rho}{\rho}$ where $\rho$ and $\rho_{s}$ are the water and solid particles density, respectively, $g$ is acceleration of gravity and $\nu$ is molecular viscosity.

The physical meaning of this expression is quite clear. The basic of the formulae is the ratio of near-bottom turbulent energy production $\frac{v_{*}^{3}}{\left(v^{2} g^{-1}\right)^{\frac{1}{3}}}$ to the energy flux of particles settling $g \omega$.

The next point is the choice of the reference level $a$. Some researches propose to take fixed reference level (for example, 0.2,0.3, $1.0 \mathrm{~m}$ above bottom), where the concentration could be measured reliable enough (Kos'yan, et al, 2000; Clarke et al, 1982). But, in this case, the extrapolation of the results beyond the experimental range of the parameters is at least doubtful. In our solution, the reference level is considered not fixed but dependent on the flow parameters. It is clear that the reference level should be chosen at the level where some relationship between SPM concentration and some of its controlling parameters remains invariant. Taking into account the structure of the formulae (3.7), (3.8) it is reasonable to chose settling velocity of sediment particles $\omega_{i}$ as an argument and the relationship $C_{a i} \sim \omega_{i}^{-1} p_{i}$ as an invariant relationship. The arguments governing the reference level location 
are the following: flow depth $H$, bottom shear stress $v_{*}$, molecular viscosity $\nu$ and acceleration of gravity $g$. The individual characteristics of sediment particles $\left(\omega_{i}\right)$ are not included because the reference level should be the same for the whole assembly of inhomogeneous particles. Using the experimental data, partially described in Antsyferov, Debol'skii, 1997; Antsyferov et al, 1999 and invoking the dimenshional analysis we propose the following expression for the reference level:

$$
a=5.2\left(\frac{v_{*} \eta H^{2}}{g}\right)^{0.25} .
$$

This approach allows reliable finding $C_{a}$ and $C_{a, i}$ in the range of parameters that covers both laboratory and field conditions (Kantardgi, Antsyferov, 1999). Another advantage of the expressions (3.7), (3.8) is their applicability for the case of unbroken waves as well as for combined wave-current flow over erodible bed. In these cases the bottom shear stress $v_{*}$ should be substituted by an effective value $v_{* e f}$. The latter is defined as the value that leads to the same result compared to the effect produced by the real $v^{*}(t)$, i.e. the same average value $\overline{C_{a}}(t)$.

4. However, the superposition principle is inapplicable for the case of the mass start of particles motion when coarse particles can be disturbed from the rest not only by the flow but by moving finer particles as well. This limitation extends to the problem on determination of parameters of bed ripples formed as solid bodies because their size is controlled by the whole ensemble of particles or by their average characteristics, in prognostic models.

5. Two bottom relief conditions are considered in the present study, namely flat bed and rippled bed. The bottom roughness is controlled by the particles size only for the flat bed but, for rippled bed, these are parameters of the ripples that play the role of roughness factor. The large-scale forms of bottom relief are treated by the flow as topography elements.

\section{The first order models}

The first order models, as was indicated above, predict vertical distribution of concentration and composition of suspended sediment averaged for half of tidal period, one or several tidal periods. For this approximation, the choice of effective characteristics of the flow is of the first importance for finding the relationship between SPM concentration and hydro-dynamical parameters of the flow. The averaged value $\overline{C_{a}}(t)$ for the corresponding time period $T$ is the criterion for this choice. Taking into account that $C_{a}$ is proportional to $v_{*}^{3}$ (see (3.8)) and is independent of $H$, which should calculate the desired effective value of bottom shear stress as $v_{* e f}=\left(\frac{1}{T} \int_{0}^{T} v_{*}^{3} d t\right)^{\frac{1}{3}}$, and the effective depth as $H_{e f}=\bar{H}(t)$.

At first let us consider the problem on SPM transport over a flat bed. It should be remembered, however, that they are laboratory experiments that form the basis of this solution. The authors have not found any correct enough field experiments. But for the second part of the problem, i.e. for the relationship between the velocity $u_{c}$ measured at 
some level $y$ the current velocity profile $u(y)$ and $v_{*}$ the reliable base of laboratory and field observational data is available. Using well approved relationships

$$
v_{*}=\alpha \kappa \bar{u},
$$

where $\bar{u}$ is the depth-averaged current velocity, and

$$
u(y)=(1+\alpha) \bar{u}\left(\frac{y}{H}\right)^{\alpha},
$$

one can easily find

$$
\begin{aligned}
& v_{*}=\alpha \kappa(1+\alpha)^{-1}\left(\frac{y}{H}\right)^{-\alpha} u(y), \\
& u(y)=u_{c}\left(\frac{y}{c}\right)^{\alpha} .
\end{aligned}
$$

A number of known empirical formulae for the value $\alpha$ can be subdivided into those suitable for laboratory experiments or for field observations. We use the formula proposed by Yu and Fang, 1995:

$$
\alpha=\frac{1}{4.7}\left(\frac{d}{H}\right)^{0.06},
$$

because it is applicable for both laboratory and field condition for bottom sediment of mean size $\bar{d}<0.5 \mathrm{~mm}$.

Now, on the base of obtained relationships the depth-averaged settling velocity of suspended particles $\bar{\omega}(y)$ can be easily found:

$$
\bar{\omega}(y)=\frac{1}{C(y)} \sum_{i=1}^{n} C_{i}(y) \omega_{i}=\frac{\sum_{i=1}^{n} R_{i}(y) F_{i}^{Q(y)} p_{i}}{\sum_{i=1}^{n} R_{i}(y) F_{i}^{Q(y)} \omega_{i}^{-1} p_{i}},
$$

as well as the other statistical characteristics of sediment distribution by their settling velocitics. The corresponding characteristics of grain size distribution can be found as well using known relationships between grain size and settling velocity.

With the advent of bed ripples the behaviour of sediment pick up changes noticeably due to action of vortices arising behind the ripples crests. The microforms become now the main roughness element. And, because the bottom shear stress $v_{*}$ is the main argument in our solution, the problem is reduced to finding the relationship between $v_{*}$ and the dimensions of microforms. One of the most reliable relationships of this kind is that by Grant and Madsen, 1982:

$$
\frac{u(y)}{\nu_{*}}=\frac{1}{\kappa} \ln \frac{y}{h_{r} \beta}+0.2,
$$

where $h_{r}$ and $\beta$ are the height and the steepness of the ripples.

It is evident now that the reliability of the solution depends crucially on the reliability of the methods for finding parameters of ripples. If there are no direct observations, 
the empirical methods can be used for the lack of good theoretical solutions. And the reliability of empirical methods is in direct dependence upon their experimental basis. We consider the time proved methods by Znamenskaya, 1992 and Zheleznyakov, Debol'skii, 1971, developed on the base of carefully selected laboratory and field experiments, to be the most reliable by this criterion.

The graphic criteria by Znamenskaya in coordinates $\frac{\bar{u}}{\bar{u}_{c r}}$ against $F_{r}=\frac{\bar{u}^{2}}{g H}$ allow fixing the areas of different bottom forms existence as well as their steepness $\beta$. Depth-averaged current velocity $\bar{u}_{c r}$ corresponding to the mass starting of particles motion and ripple height $h_{r}$ can be calculated by the formulae proposed by Zheleznyakov and Debolskii:

$$
\begin{aligned}
& \bar{u}_{c r}=1.4 \bar{\omega}\left[\lg \frac{H}{\bar{d}} \frac{1}{\sqrt{\rho_{*}}+1}\left(\frac{\sqrt{g \bar{d}}}{\bar{\omega}}+1\right)\right]^{\frac{7}{6}}, \\
& h_{r}=1.25 H\left(\frac{\bar{u} \bar{d} \bar{\omega}}{\bar{u}_{c r} H \sqrt{g H}}\right) .
\end{aligned}
$$

For known values $\bar{d}, \bar{\omega}, \rho_{*}, H$ and $u_{c e f}$ and chosen initial estimates for $v_{*}, h_{r}$ and $\beta$ the desired value of bottom shear stress $v_{*}$ can be found by simple iterative process. Now the current velocity vertical distribution can be easily described too.

Thus, for the case of rippled bed the solution is again expressed by formulae (3.3)-(3.9) where $v_{* e f}$ is found by (4.7)-(4.9) using the criteria mentioned above.

\section{The second order models}

In the second order models the sediment-laden tidal flow will be modelled by a series of $j=1, \ldots, m$ consecutive steady states.

In this more rigorous posing the study can be extended and, in addition to the problems of the first stage, those on sediment discharge and on the total sediment transport can be considered. These problems are of no less importance for geophysical prognosis as well as for the practical objectives.

The question of reasonable averaging time i.e. of the duration of time steps is of fundamental importance for the second order models. Two factors should be taken into account. On the one hand, it is required of the averaging time for hydrodynamical parameters to be considerably higher than the characteristic period of energetic turbulent structures and, at the same time, it must be much less than tidal period (Rossinskii, Debol'skii, 1980 and others). On the other hand, the time step must be comparable to the minimum time interval needed for bottom relief formation under averaged flow characteristics. The relaxation time for suspended sediment distribution is much less than needed under conditions mentioned (Zyryanov, Reshetkov, 1998) and hence this factor is ignored.

Nevertheless no objective enough criterion has been found for estimation by both factors. It is known that there is no sharp minimum in the horizontal velocity spectrum that separates high frequency turbulence from low frequency tidal oscillations, i.e. the spectral density behaviour is monotonic. So the choice of averaging time is, to some extend, a matter of researcher's experience and taste (Marchuk, Kagan, 1991). We find 
the low limit of averaging time by the threshold of bottom shear stress for sediment pickup. For the condition considered $(H \sim 5 \div 10 \mathrm{~m}, d \sim 0.1 \div 0.4 \mathrm{~mm})$ it is estimated from quarter to half of an hour.

Up to now, there are no conventional estimates for the time needed for ripples formation. But it is known to be dependent on relationship between the current velocity and the parameters of particles mobility. This time is estimated at about an hour, by the observational experience for the bed sediment mean size of $0.03-0.04 \mathrm{~cm}$ and the velocity of $25 \div 30 \%$ over the threshold value (Neill, 1968). For the intensive sediment resuspension regime this time decreases up to ten minutes. So the tendency of decrease of minimum average time with velocity increase is found by both factors.

So, from these considerations, each time interval from zero to the tidal period can be divided into some steps from one hour to quarter of hour long. This gives about ten steps for semidiurnal tide. This choice can hardly be considered as well founded but probably it is acceptable as a first approximation.

The other important point is the vertical profile of current velocity at each step. It was mentioned above that the velocity profile can be thought of as logarithmic one at least at the first meters above bottom during about $90 \%$ of tidal period. "Non-logarithmic" part of tidal period is usually related to the action of lower velocities that are incapable of sand sediment resuspension. For the case of flow propagating over large-scale bed forms with the length comparable to water depth the velocity distribution is more complicated. But this case is not considered in our study.

So, one can use the solutions given above for each $j$-th velocity step taking corresponding values of the depth and bottom shear stress. The SPM concentration can therefore be found by the formulas (3.1) - (3.9) where the values related to each $j$-th step are used, i.e.:

$$
\begin{aligned}
& C_{i, j}(y)=C_{a, i, j} R_{i, j}(y) F_{i, j}^{Q(y)}, \\
& C_{j}(y)=\sum_{i=1}^{n} C_{i, j}(y) .
\end{aligned}
$$

Sediment flux for $i$-th fraction during the same step can be calculated as follows:

$$
G_{i, j}(y)=C_{a, i, j} R_{i, j}(y) F_{i, j}^{Q(y)} u_{c, j}\left(\frac{y}{c}\right)^{\alpha},
$$

and the total flux of inhomogeneous sediment will be

$$
G_{j}(y)=\sum_{i=1}^{n} G_{i, j}(y) .
$$

Hence, the sediment transport for $m$ time steps is equal

$$
W_{j}(y)=\sum_{i=1}^{m} C_{a, i, j} R_{i, j}(y) F_{i, j}^{Q(y)} u_{c, j}\left(\frac{y}{c}\right)^{\alpha} t_{j},
$$

for $i$-th fraction and

$$
W(y)=\sum_{i=1}^{n} W_{i}(y),
$$


for the total mass of sediment.

Here $t_{j}$ is the duration of $j$-th velocity step. Ripples parameters, velocity profile $u(y)$ and values $v_{* e f}$ are calculated for each step by the same methods as in the first order model.

The problem on vertical distribution of average settling velocity and the other statistical characteristics of suspended particles can be found as before. For example, the average settling velocity of particles at the horizon $y$ for $j$-th step is calculated as follows:

$$
\bar{\omega}_{j}(y)=\frac{1}{C_{j}(y)} \sum_{i=1}^{n} C_{i, j}(y) \omega_{i}=\frac{\sum_{i=1}^{n} R_{i, j}(y) F_{i, j}^{Q(y)} p_{i}}{\sum_{i=1}^{n} R_{i, j}(y) F_{i, j}^{Q(y)} \omega_{i}^{-1} p_{i}},
$$

and for calculation the average settling velocity for time interval of $m$ steps the additional summation over $j$ is needed:

$$
\bar{\omega}_{j}(y)=\sum_{j=1}^{m} \frac{1}{C_{j}(y)} \sum_{i=1}^{n} C_{i, j}(y) \omega_{i} .
$$

The corresponding characteristics of sediment granulometric distribution can be found by similar way. Verification of the mentioned above method is presented in the second part of this work.

\section{References}

1. Antsyferov S. M., Measurements of suspended sediment transport in river mouths and estuaries, Hydrotech. Constr. Plenum Publ. Corp. 32 (4) (1998) 193-197.

2. Antsyferov S. M., Basinski T., Pykhov N. Y., Measurement of suspended sediment concentration, Coastal Eng. 7 (1983) 145-166.

3. Antsyferov S. M., Debol'skii V. K., Distribution of suspended matter concentration in steady-state flow over an eroding bed. Water Resources 24 (3) (1997) 244-250.

4. Antsyferov S. M., Kos'yan R. D., Suspended Sediment on the Upper Shelf, Moscow. "Nauka" Publ. House, 1986.

5. Antsyferov S. M., Kos'yan R. D., Study of suspended sediment in the coastal zone, Coastal Eng. 14 (1990) 147-172.

6. Antsyferov S. M., Pykhov N. V., Dachev V. Zh., Dynamics of Suspended Sediments, Dynamical Processes in Coastal Regions, Results of the Kamchia Int. Project. Sofia.: Publ. House of the Bulg. Acad. of Sci., 1990.

7. Clarke T. L., Lesht B. M., Yong R. A., et al., Sediment resuspension by surfase-wave action: an examination of possible mechanisms, Mar. Geol. 49 (1982) 43-59.

8. Debol'skii V. K., Antsyferov S. M., Akivis T. M., The Prediction Problems of Suspended Sediment Distribution in Channel and Tidal Flow, Water Problems at the Edge of the Century, Moscow. "Nauka" Publ. House, 1999.

9. Eims D., Flocculation of suspended sediment matter in coastal waters, Pẳrticle Flux in the Ocean, Mitt. Geol.-Paleont. Inst. Univ. Hamburg. Heft 62, 1982. 
10. Grant W. D., Madsen O. S., Moveable bed roughness in unsteady oscillatory flow, $J$. Geophys. Res. 87 (1982) 469-481.

11. Kantardgi I. G., Antsyferov S. M., Development of coastal sediment modelling, Wave and current co-action, $5^{\text {th }}$ Int. Conf. on Coastal and Port Eng. in Developing Countries, Proc. COPEDEC. Cape Town., 1, 103-114.

12. Kos'yan R. D., Pykhov N. V., Edge B. L., Coastal Processes in Tideless Seas, ASCE Press, 2000.

13. Marchuk G. I., Kagan B. A., Dynamics of Ocean Tides, SPB, Gidrometeoizdat Publ. House, 1991.

14. Neill J., Note on initial movement of coarse uniform bed material, J. Hydr. Div., Proc. of ASCE, 2, 1968.

15. Rossinskii K. I., Debol'skii V. K., Fluvial Sediments, Moscow. "Nauka" Publ. House, 1980.

16. Torfs H., Willjamson H., Huysentruyt H., Setting and erosion characteristics of mud/sand mixtures, Proc. Coastal Dynamics'95, ASCE N. Y., 749-758, 1995.

17. Van Rijn L. C., Principles of Sediment Transport in Rivers, Estuaries and Coastal Seas, Aqua Publ., Amsterdam, 1993.

18. Yu G., Fang D., Threshold velocity of sand mixtures, Proc. $26^{\text {th }}$ Congr. of IAHR, Thomas Telford, London, 1995.

19. Zheleznyakov G. V., Debol'skii V.K., On Rippled Movement of Sediments of Different Density, Dokl. VASKHNIL, 2, 1971.

20. Znamenskaya N. S., Hydraulic Modelling of Channel Processes, SPb, Gidrometeoizdat Publ. House, 1992.

21. Zyryanov V. N., Reshetkov A. B., Sediment transport and sea floor transformation by tidal waves in shallow water, Oceanology 38 (5) (1998) 674-686.

Received November 14, 2003

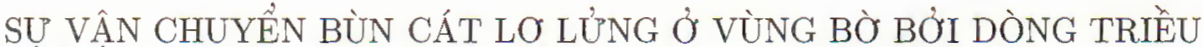 PHẦN I: CÁC MÔ HINH PHÂN BỐ THĂNG ĐÚNG CÁC HẠT LO LỦNG}

Mục tiêu của nghiên cứu này là phát triển phương pháp dự báo các đặc trựng phân bố theo phương thẳng đứng của bùn cát lơ lựng do dòng triều với thời gian trung bình hoá là chu kỳ triều (mô hình bậc nhất) hoặc nhó hơn nhiều lần (mô hình bậc hai). Đáy biển được coi là có khả năng bị xói và có khà năng tạo thành gợn sóng lăn tăn.

Phần I: Các nghiên cứu lý thuyết và trong phòng thí nghiệm đối với dòng chây dừng có hạt lơ lưng được sử dụng để phát triển lời giải. Nồng độ của bùn cát không đồng nhất được xem như là tổng hợp của nhóm hạt đồng nhất chuyển động với cùng một quy luật. Trong mô hình bậc nhất, các đặc trưng thuy động lực học của dòng triều được mô tả bởi các giá trị hữu hiệu hằng số, còn mô hình bậc hai đòng triều được mô tá bởi chuỗi các trạng thái dừng liên tiếp. 